\title{
Secondary hemochromatosis
}

\section{Hemocromatosis secundaria}

Emmanuel A. Lazcano-Díaz" *, Diego X. Chango-Azanza², Zuilma Y. Vásquez-Ortiz, Sandra G. Rosales-Uvera², Mónica Chapa-Ibargüengoitia², Consuelo Orihuela-Sandoval', and José P. Hernández-Reyes ${ }^{1}$

${ }^{1]}$ Department of Clinical Echocardiography; ${ }^{2]}$ Department of Computed Tomography and Cardiac Magnetic Resonance. Instituto Nacional de Ciencias Médicas y Nutrición Salvador Zubirán, Mexico City, Mexico

The case of a 48-year-old man with a four-year history of myelodysplastic syndrome and multiple transfusions due to anemia, who arrived at the emergency department with a six-week history of symptoms of heart failure, is presented. Laboratory tests showed high-sensitivity troponin I levels at $67 \mathrm{ng} / \mathrm{mL}$, B-type natriuretic peptide at $2,386 \mathrm{pg} / \mathrm{mL}$ and serum ferritin at $4,412 \mathrm{ng} / \mathrm{mL}$. Transthoracic echocardiogram showed dilation of all four cavities with right predominance (Fig. 1A). New echocardiography techniques such as ventricular mechanics with speckle tracking confirmed dilated cardiomyopathy at advanced stage with severe mechanical dysfunction and longitudinal strain of $-10 \%$ (Fig. 1B), circumferential strain of $7.7 \%$ and radial strain of $16 \%$; interestingly, there was a $-7^{\circ}$ negative twist (Fig. 1C) caused by basal and apical rotation direction reversal. Cardiac magnetic resonance showed dilation and severe biventricular dysfunction, with left ventricular ejection fraction of $22 \%$ and right of $27 \%$. Iron infiltration-induced cardiomyopathy was suspected due to patient history, and cardiac magnetic resonance with T2*-weighted sequence was therefore performed, which confirmed moderate cardiac iron infiltration with a value of $17 \mathrm{~ms}$ and a T2*-weighted liver value of 27 ms (Fig. 1D). Short axis late gadolinium enhancement showed diffuse fibrosis of epicardial predominance (Fig. 1E). These findings are characteristic of the iron overload (hemochromatosis) infiltrative cardiomyopathy dilated phenotype at advanced stages of the disease.

\section{Funding}

None.

\section{Conflicts of interest}

The authors declare that they have no conflicts of interest. 2604-7063 / @ 2020 Instituto Nacional de Cardiología Ignacio Chávez. Published by Permanyer. This is an open access article under the CC BY-NC-ND license (http://creativecommons.org/licenses/by-nc-nd/4.0/).
Available online: $20-10-2021$ Arch Cardiol Mex (Eng). 2021;91(3):339-340 www.archivoscardiologia.com 


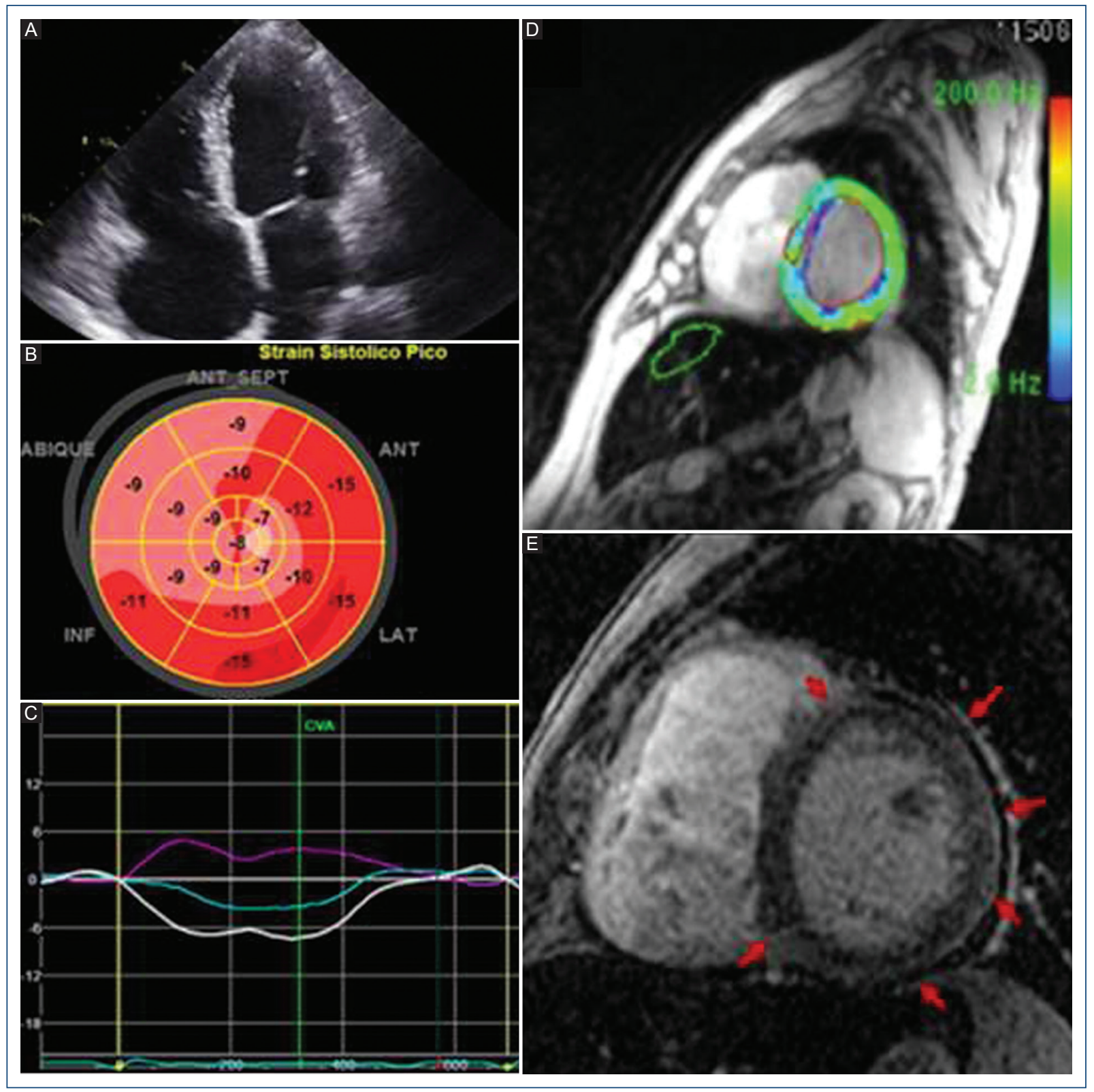

Figure 1. A: Transthoracic echocardiogram: four-chamber apical view. B: Polar map showing global longitudinal strain decrease. C: Twist inversion (white line) with negative value $\left(-7^{\circ}\right)$. D: T2*-weighted cardiac magnetic resonance sequence on the short axis at the base level confirming iron infiltrative cardiomyopathy. E: Late gadolinium enhancement at the short axis level showing predominantly epicardial fibrosis (red arrows).

\section{Ethical disclosures}

Protection of human and animal subjects. The authors declare that no experiments have been performed on humans or animals for this investigation
Confidentiality of data. The authors declare that no patient data appear in this article.

Right to privacy and informed consent. The authors declare that no patient data appear in this article. 